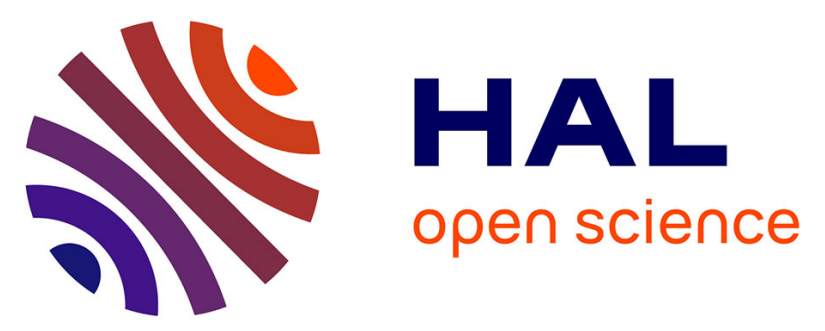

\title{
Screening for children's depression symptoms in Greece: the use of the Children's Depression Inventory in a nation-wide school-based sample
}

George Giannakopoulos, Maria Kazantzi, Christine Dimitrakaki, John

Tsiantis, Gerasimos Kolaitis, Yannis Tountas

\section{To cite this version:}

George Giannakopoulos, Maria Kazantzi, Christine Dimitrakaki, John Tsiantis, Gerasimos Kolaitis, et al.. Screening for children's depression symptoms in Greece: the use of the Children's Depression Inventory in a nation-wide school-based sample. European Child and Adolescent Psychiatry, 2009, 18 (8), pp.485-492. 10.1007/s00787-009-0005-z . hal-00535137

\section{HAL Id: hal-00535137 https://hal.science/hal-00535137}

Submitted on 11 Nov 2010

HAL is a multi-disciplinary open access archive for the deposit and dissemination of scientific research documents, whether they are published or not. The documents may come from teaching and research institutions in France or abroad, or from public or private research centers.
L'archive ouverte pluridisciplinaire HAL, est destinée au dépôt et à la diffusion de documents scientifiques de niveau recherche, publiés ou non, émanant des établissements d'enseignement et de recherche français ou étrangers, des laboratoires publics ou privés. 


\title{
Screening for children's depression symptoms in Greece: the use of the Children's Depression Inventory in a nation-wide school-based sample
}

\author{
George Giannakopoulos • Maria Kazantzi • \\ Christine Dimitrakaki · John Tsiantis · \\ Gerasimos Kolaitis · Yannis Tountas
}

Received: 22 July 2008/ Accepted: 19 January 2009/Published online: 3 March 2009

(C) Springer-Verlag 2009

\begin{abstract}
The objective of this study is to determine the level of depressive symptoms among a sample of Greek children aged 8-12 years, as measured by the Greek Children's Depression Inventory (CDI), as well as to examine CDI's psychometric properties. A nationwide school-based sample of 650 children was initially recruited and depressive symptoms were assessed with the CDI among 538 children who provided all relevant information. Statistical evaluation included assessment of CDI internal reliability, test-retest reliability, determination of age, gender and socioeconomic status (SES) effects. Based on the distributions of CDI scores observed in this normative sample, a recommended cutoff score, identifying a high probability of serious levels of depressive symptoms that need to be further evaluated, was defined. Internal reliability and test-retest reliability were satisfactory and the expected associations with age and gender were observed. High SES was correlated with significantly less depression symptoms. The prevalence of depressive risk, when the cutoff point of 19 or 13 was taken as threshold, was much
\end{abstract}

G. Giannakopoulos · M. Kazantzi · C. Dimitrakaki ·

Y. Tountas $(\bowtie)$

Centre for Health Services Research, Medical School,

University of Athens, 25 Alexandroupoleos str,

11527 Athens, Greece

e-mail: chsr@med.uoa.gr

J. Tsiantis

Association for the Psychosocial Health of Children

and Adolescents (A.P.H.C.A.), 19, Aghiou Ioannou Theologou

St, 15561 Athens, Greece

\section{G. Kolaitis}

Department of Child Psychiatry, Athens University Medical

School, "Aghia Sophia” Children's Hospital,

Thivon \& Levadias, 11527 Athens, Greece lower than those obtained from studies in other countries. The cutoff point of 15 , corresponding to 90th percentile of the present sample, may be used as a screening threshold for further assessment. The present results are encouraging providing evidence about the psychometric properties of the CDI and implications for child mental health promotion planning in Greece. Further validation of the CDI against other measures and psychiatric diagnoses is needed.

Keywords Children's Depression Inventory · Greece · Reliability · Screening

\section{Introduction}

International population-based studies suggest that roughly $5 \%$ of pre-pubertal girls and $1.5 \%$ of pre-pubertal boys manifest clinical levels of depression [22]. Similar prevalence figures are obtained when formal psychiatric diagnostic instruments are administered [1]. Depressive disorders are unidentified to a great extent in general child populations, despite the fact that depressive symptoms are among the commonest self-reported psychiatric complaints in childhood [22, 50]. For screening purposes, the use of brief measures, such as questionnaires, can select 'at risk' cases for further assessment [52]. Still, there is a lack of appropriate instruments in small linguistic areas, such as Greece.

The Children's Depression Inventory (CDI) [30] is the most widely used and best studied scale for depressive symptoms in children [41]. The CDI assesses core symptoms of depression, combining characteristics of the clinical and dimensional evaluation (i.e. it covers depressive symptoms according to the DSM IV [3] and the items are scored quantitatively reflecting growing severity of 
symptoms). Previous research has shown that the CDI is adequately reliable and valid with respect to depressive symptoms [9, 14, 25, 31, 33, 44, 47, 49, 56]. In general populations the CDI mean score and standard deviation is around $9 \pm 7$, and its internal consistency evaluated with Cronbach's alpha ranges from 0.71 to 0.87 [8, 32, 42]. The test-retest reliability has been shown moderate to high depending on the time interval and the type of sample (i.e. clinical or general population) [24, 50].

A meta-analysis on the CDI conducted in the USA [55] has shown that girls' CDI scores tend to stay steady from ages 8 to 11 and increase between ages 12 and 16, whereas boys' depression scores remain stable from ages 8 to 16 , except for a high CDI score at age 12. Additionally, girls seem to report slightly lower CDI scores than boys' during childhood, but higher from the age of 13 [55]. The same study showed no differences in depression, as measured by the CDI, across socioeconomic status (SES) of children, although other studies do indicate that a low SES is correlated with a greater prevalence of depression [5, 45]. Twenge and Nolen-Hoeksema [55] have suggested, in their meta-analysis, that this discrepancy can be attributed to methodological issues since very few studies of the CDI have had sufficient numbers of children from different socioeconomic backgrounds to allow examination of mean scores across all SES levels [55]. Other researchers suggest that the introduction of mediating factors in the study of SES-depressive symptoms relationship reduces the magnitude of this association. In other words, SES may not remain associated with depressive symptomatology after adjustment for a cluster of factors (i.e. family structure, ethnicity, parental health status, parental education, inequalities in education, welfare services and health care use as well as social exclusion) that can either increase the risk for depressive symptomatology through imposing psychosocial stressors or/and put barriers to the appropriate diagnosis and treatment of depression [6, 16, 39].

Screening based on the CDI often uses reported information on suggested cutoff scores. The cutoff score of 19, corresponding to the 90th percentile, has been considered suitable for screening in the general population, while the cutoff score of 13 , corresponding to the 65th percentile, has been suggested as being adequate for screening purposes in clinical samples [52]. However, with regard to clinical samples, there is a substantial body of research indicating that CDI cutoff scores cannot accurately distinguish between depressed and non-depressed individuals [10, 24, $27,48]$. It has been shown that in clinical samples, CDI can be used as a preliminary continuous measure of depressive symptoms rather than a single evaluation instrument for a diagnosis of depression [10].

In Greece, there are no sufficient epidemiological data in child depression. A population-based study of 1,325 adolescents [36] has reported a prevalence rate for depressive symptomatology around $14.5 \%$. Another Greek study [28] reported that $8.6 \%$ in a school-based sample of 323 children aged 10-13 years indicated a high level of depressive symptoms (i.e. 19-28 CDI total score) and $21.9 \%$ displayed mild depressive symptomatology (i.e. 1018 CDI total score). Few published studies have investigated emotional and behavioural problems among Greek school-aged children and adolescents with regard to their school performance or in comparison to data from different cultural settings $[4,23]$. The results of these studies present increased rates of children with emotional or/and behavioural problems compared to results of international studies. This discrepancy is partly attributed to socio-cultural differences in organising mental health services and the way that informants respond to the items of various questionnaires [37, 46]. Another reason for the relatively limited published research is the lack of screening instruments in Greek that have been developed or adapted against agreed scientific criteria and attributes [54]. As the European interest in mental health prevention and promotion services is expanding, availability of good quality instruments at a national level is important in identifying subgroups of children at-risk, in determining the emotional burden of a particular disease or disability, in evaluating health services needs, and in aiding the promotion of policies related to child health.

The aim of the present study was twofold: (1) to provide a first examination of reliability issues, age, gender, and SES effects on the Greek CDI and (2) to assess the prevalence of depressive symptoms as measured by the CDI in a nation-wide school-based sample of Greek children.

\section{Method}

Participants and procedure

The study was conducted during the year 2006 in a nationwide school-based population sample of 650 Greek children (306 boys) aged 8-12 years (mean age: 10.16 years, SD: 1.193). A questionnaire was administered to each participant. One hundred and two children (15.7\%) were finally excluded from the analysis due to missing values in any of the questionnaire items. The final sample consisted of 548 children (255 boys; mean age: 10.20 years, SD: 1.168). The children finally included in the analysis did not differ from the excluded children in terms of sex or school grade they attended $\left(\chi^{2}=0.213, p=0.644\right.$ and $\chi^{2}=$ $3.403, p=0.334$, respectively). The sampling was random and based on the age and sex distribution of school children according to data from the National Census of 2001, living in the 51 geographical sectors of the country. Schools and 
school grades had been randomly selected in each sector. For each school grade the number of students to participate in the survey was calculated based on the number of students in each grade in the respective sector. The regional School Health Coordinators (HCs) in each sector conducted student sampling and collected data in two phases. During the first phase, students were selected randomly from classroom name lists and were administered the questionnaires to be filled out at home, accompanied with an information letter for parents, a consent form and a parental form of questionnaire providing information regarding socio-demographic parameters. During the second phase, the HCs collected the questionnaires from students who had obtained written informed consent by their parents. Two to three weeks later retest questionnaires were mailed directly from the study research center to a randomly selected $10 \%$ of the sample. The national Pedagogical Institute gave ethical approval to the study. Written parental informed consent and child assent were obtained.

\section{Measures}

\section{The Children's Depression Inventory}

There are 27 items quantifying symptoms such as depressed mood, hedonic capacity, vegetative functions, self-evaluation and interpersonal behaviours. It covers the consequences of depression as they relate to children and functioning in school and with peers. For each item the child has three possible answers; 0 indicating the absence of symptoms, 1 the mild symptoms, and 2 the definite symptoms. The total score ranges from 0 to 54 . The translation of the instrument into the Greek language followed recommended guidelines [18]. The first step employed a forwardbackward-forward translation technique. The original English questionnaire was translated twice by two independently working translators into the Greek language. Next, all items of the two independent versions were compared in order to generate a single corrected reconciled version for each item. The items of this reconciled forward translation were then back-translated in order to be subsequently compared with the items of the original English version. This comparison was designed to provide the final version for the Greek CDI questionnaire. The second step involved a pre-test to ensure the feasibility of the translated questionnaire (ages 8-12). In the pre-test, it was shown that children older than 8 years of age could read, understand and answer all the CDI items without problems.

\section{The Family Affluence Scale}

The Family Affluence Scale (FAS) $[13,51]$ was used to assess the SES of the participating children's family. The
FAS is addressing issues of family car ownership, having their own unshared room, the number of computers at home and times the children spent on holiday in the past 12 months. The FAS has been characterized as a valid, and easy to answer by children, measure of socio-economic status [7]. In the present study, the FAS was classified in seven categories (from 0 the lowest, to 7 the highest FAS category) and was recoded into three groups in the analysis (low, intermediate and high FAS level). Based on the available literature on the effects of SES on child emotional health, it was expected to find higher CDI scores in children of lower SES in comparison to children of higher SES.

\section{Statistical analysis}

Internal consistency reliability was determined by the calculation of Cronbach's alpha coefficient [12] and Guttman and Spearman-Brown coefficients [20]. Because higher level of reliability increases statistical power, a minimum reliability of 0.70 for measures used in-group comparisons has been recommended [42]. Test-retest reliability was determined by administering the CDI questionnaire on two separate occasions 3-4 weeks apart to a randomly selected $10 \%$ of the sample. The Spearman Rank Correlation Coefficient was calculated to assess the test-retest reliability with coefficients greater than 0.60 considered adequate. Floor and ceiling effects were calculated based on the percentages of scores at extremes of the scaling range [38]. Floor and ceiling effects were considered to be present when $15 \%$ of respondents had the minimum or maximum possible scores on a given dimension, respectively. Comparisons on categorical variables were carried out by $\chi^{2}$ test, while the differences between the mean values of continuous data for different groups were analyzed with the non-parametric Mann-Whitney $U$ test and Kruskal-Wallis test. Three cutoff points of the total CDI score were introduced in order to roughly identify subgroups at risk of developing depressive disorders: the cutoff points of 19 and 13, using evidence of the existing literature $[15,19,26,31,35]$, as well as the cut-off of 15 , which corresponded to the 90th percentile of the present study's population. A significance level of 0.05 was applied in all comparisons. Statistical analysis was performed with STATA 8.0.

\section{Results}

The 27 items of the CDI questionnaire were filled in by 548 school-aged children (228 males), aged 10.20( \pm 1.168$)$ years. There was no difference in the mean age for boys and girls $(p=0.175)$. Split half reliability Guttman and 
Spearman-Brown coefficients were 0.795 and 0.798 , respectively. Overall internal consistency (Cronbach's alpha) of the CDI was 0.805 ( 0.833 for girls and 0.757 for boys). Item total-score correlation coefficients (Spearman) for the whole sample ranged from 0.252 to 0.595 and were all significant at the $p<0.001$ level. Test-retest reliability analysis showed ICCs above 0.60 for the total score $(0.82$ and 0.62 for girls and boys, respectively).

The mean total score for the whole sample was 7.11 (SD: 5.535, range 0-38, skewness: 1.346), 6.70 (SD: 4.851) and 7.50 (SD: 6.095) for the boys and girls, respectively. The total CDI score was higher for the girls of our sample, though it did not reach the level of significance (MannWhitney test $0.889, p=0.374$ ). There were no significant differences in the CDI mean scores between the different age groups of our sample (Kruskal-Wallis test $=4.344$, $p=0.36$ ). No ceiling effects were detected for the total CDI since none of the respondents collected the highest possible score. No floor effect was present either for the total CDI score $(4.74 \%$ of the children reported no depressive symptoms during the past 2 weeks).

Twenty-three of the five hundred and forty eight children who completed all the relevant fields of the questionnaire (4.20\%) had a CDI score higher than or equal to 19 . Over the threshold of 13 were 82 of 548 children $(14.96 \%)$, whereas a mean score higher than or equal to 15 corresponded to the 90th percentile (Table 1).

For 538 of the 548 children, who answered the 27 CDI items, information regarding age and the SES of the family were also recorded. The participants who did not fill in the relevant fields were excluded from further analysis, as presented in Table 2. For the final group of 538 children included in the analysis, associations were investigated, between the total CDI score and the gender, age and SES of the family, as declared by the FAS index. In Table 2 we present mean scores $( \pm \mathrm{SD})$ divided by gender, age and FAS index, as well as the absolute and relative frequencies of children exceeding the 19-, 15- and 13-point threshold in the subgroups. CDI scores among the three FAS levels were significantly different $(p=0.03)$ with a decrease in CDI total score from low to middle and from middle to upper FAS level $(7.79 \pm 5.682,6.94 \pm 5,290$ and $6.11 \pm 5.110$, respectively). Among the children with a total CDI score over the threshold of 13 , there was a nonsignificant but indicative difference regarding the socioeconomic status $(p=0.06)$. Chi-square analyses also revealed a significant difference in gender $\left(\chi_{(1)}^{2}=6.706\right.$, $p=0.011$ ), where females had in higher percentage a score equal to or higher than 15 , but this difference was not confirmed for the threshold score of 13 . The variation of depressive symptomatology between genders as a function of age was also examined (Table 3): boys had higher CDI mean scores than girls at younger ages ( 8 and 9 years of age)
Table 1 Socio-demographic characteristics of total sample and final group, after the exclusion of participants who did not complete all relevant fields

\begin{tabular}{lcc}
\hline & Total sample $N(\%)$ & Final group $N(\%)$ \\
\hline Sex & & \\
Male & $255(53.5)$ & $252(46.8)$ \\
Female & $293(46.5)$ & $286(53.2)$ \\
Missing data & - & - \\
Total & $548(100)$ & $538(100)^{*}$ \\
Age (years) & & \\
8 & $37(6.7)$ & $37(6.9)$ \\
9 & $133(24.3)$ & $129(24.0)$ \\
10 & $149(27.2)$ & $146(27.1)$ \\
11 & $143(26.1)$ & $85(15.8)$ \\
12 & $86(15.7)$ & $538(100)^{*}$ \\
Total & $548(100)$ & \\
FAS & & $147(27.3)$ \\
Low & $147(26.8)$ & $263(48.9)$ \\
Middle & $263(48.0)$ & $128(23.8)$ \\
High & $128(23.4)$ & - \\
Missing data & $10(1.8)$ & $538(100)^{*}$ \\
Total & $548(100)$ & \\
& &
\end{tabular}

$* p<0.05$

whereas for ages 10-12 girls tend to declare more depressive symptoms, as reflected from the higher mean CDI score. However, this difference did not reach the level of significance. A similar conclusion is drawn when the excess of the cutoff scores is used as endpoint: girls aged 10 or 11 years exceed the cutoff scores of 13 and 15 at a higher percentage than their peer boys. However, this difference was not confirmed for the 12-year-old adolescents. The respective analyses for the clinical threshold of depression (score equal to or higher than 19) revealed no difference between males and females, partially expected due to the small number of observations, as presented in Table 3.

\section{Discussion}

The aim of the present study was to examine psychometric issues of the Greek CDI and to estimate the rates of depressive symptomatology with the use of the above measure in Greek children aged 8-12 years.

The internal consistency of the Greek CDI was good and comparable to the internal consistency of the English and other versions [8]. The test-retest reliability was also adequate and consistent with previous research [34].

The present analysis showed no significant difference in levels of depressive symptoms between boys and girls and across children's ages. This finding agrees with a body of 
Table 2 CDI scores and prevalence of depressive risk according to sex, age and socioeconomic status (FAS) for the final group included in the analysis

\begin{tabular}{lccccc}
\hline & $N(\%)$ & Mean (SD) & $\begin{array}{l}\text { CDI } \geq 19 \\
N(\%)\end{array}$ & $\begin{array}{l}\text { CDI } \geq 15 \\
N(\%)\end{array}$ & $\begin{array}{l}\text { CDI } \geq 13 \\
N(\%)\end{array}$ \\
\hline Sex & & & & \\
Male & $252(46.8)$ & $6.66(4.885)$ & $7(2.78)$ & $16(6.35)^{*}$ & $33(13.10)$ \\
Female & $286(53.2)$ & $7.54(6.064)$ & $16(5.59)$ & $37(12.94)^{*}$ & $48(16.78)$ \\
Age (years) & & & & \\
8 & $37(6.9)$ & $6.57(4.723)$ & $0(0.00)$ & $2(5.41)$ & $6(16.22)$ \\
9 & $129(24.0)$ & $6.67(5.110)$ & $4(3.10)$ & $11(8.53)$ & $17(13.18)$ \\
10 & $146(27.1)$ & $7.03(5.667)$ & $7(4.79)$ & $16(10.96)$ & $22(15.07)$ \\
11 & $141(26.2)$ & $7.19(5.930)$ & $7(4.96)$ & $14(9.93)$ & $22(15.60)$ \\
12 & $85(15.8)$ & $8.14(5.689)$ & $5(5.88)$ & $10(11.76)$ & $14(16.47)$ \\
FAS & & & & $18(12.24)$ & $24(16.33)^{* *}$ \\
Low & $147(27.3)$ & $7.99(6.008)^{*}$ & $9(6.12)$ & $28(10.65)$ & $46(17.49)^{* *}$ \\
Middle & $263(48.9)$ & $7.19(5.494)^{*}$ & $11(4.18)$ & $7(5.47)$ & $11(8.59)^{* *}$ \\
High & $128(23.8)$ & $6.01(4.960)^{*}$ & $3(2.34)$ & $53(9.85)$ & $81(15.06)$ \\
Total & $538(100)$ & $7.13(5.555)$ & $23(4.28)$ & & \\
\hline
\end{tabular}

Table 3 Differences in depressive symptomatology between male and female children included in the analysis as a function of age

\begin{tabular}{llllll}
\hline Age (years) & $n$ & CDI score [mean (SD)] & CDI $\geq 13(n)$ & CDI $\geq 15(n)$ & CDI $\geq 19(n)$ \\
\hline 8 & 19 vs 18 & $6.89(5.163)$ vs $6.22(4.332)$ & $4 / 19$ vs $2 / 18$ & $2 / 19$ vs $0 / 18$ & $0 / 19$ vs $0 / 18$ \\
9 & 54 vs 75 & $7.20(4.935)$ vs $6.25(5.232)$ & $9 / 54$ vs $8 / 75$ & $3 / 54$ vs $8 / 75$ & $1 / 54$ vs $3 / 75$ \\
10 & 71 vs 75 & $6.08(4.994)$ vs $7.92(6.137)^{* *}$ & $7 / 71$ vs $15 / 75^{* *}$ & $4 / 71$ vs $12 / 75^{*}$ & $3 / 71$ vs $4 / 75$ \\
11 & 58 vs 83 & $6.00(4.095)$ vs $8.02(6.832)$ & $5 / 58$ vs $17 / 83^{* *}$ & $2 / 58$ vs $12 / 83^{*}$ & $1 / 58$ vs $6 / 83$ \\
12 & 50 vs 35 & $7.56(5.365)$ vs $8.97(6.104)$ & $8 / 50$ vs $6 / 35$ & $5 / 50$ vs $5 / 35$ & $2 / 50$ vs $3 / 35$ \\
Total & 252 vs 286 & $6.66(4.885)$ vs $7.54(6.064)$ & $33 / 252$ vs $48 / 286$ & $16 / 252$ vs $37 / 286$ & $7 / 252$ vs $16 / 286$ \\
\hline
\end{tabular}

$* p<0.05, * * p<0.10$

The values in each cell are presented for males versus females

literature that could not find substantial gender or age effects on depressive symptomatology [55]. In fact, the present analysis showed slight increases in depressive symptoms with children's age, finding that cross-sectional studies tend to show [11, 21]. However, the results presented here indicate that girls report slightly more depressive symptoms than boys and that more girls report depressive symptoms above the suggested cutoff score, whereas other studies consistently suggest that girls' depression scores are slightly lower than boys' during childhood $[2,55]$. When we attempted to clarify the ageby-gender interaction, it was pointed out that boys tend to have higher depression scores in younger ages whereas girls' depressive symptomatology is slightly augmented before adolescence. Though consistent to previous findings (43) this difference was not strong, in terms of statistical significance, and therefore needs to be established by future research able to offer possible implications for early identification, mental health promotion and therapeutic intervention activities targeting at possible high risk subgroups (e.g. younger school-aged boys, preadolescent girls).

Socio-economic status differences in depressive symptoms were found significant with the children of high family affluence level reporting less depressive symptoms than those of low and middle level. Although a great number of studies could not find socioeconomic effects on child depression [55], our finding agrees well with other studies in children population suggesting that a low SES was correlated with a greater prevalence of depression [5, 45]. As international studies have proposed [6, 16, 39], it could be hypothesized here that Greek children of low socioeconomic background have to cope with a number of deficiencies, barriers and psychosocial stressors in various domains (i.e. home environment, education, community life, peer relations) which increase the risk for poor developmental outcomes, emotional problems and behavioural disturbances. Additionally, the particular contextual characteristics of the Greek society may also explain this significant relationship since inequities in access, supply 
and quality of social insurance and health services in Greece [40] are likely to enhance the burden of economic disadvantage on children's mental health. Thus, national strategies of diminishing these social inequalities should be cautiously developed. Any comprehensive effort should simultaneously upgrade the social and physical environment that facilitate children's emotional well-being and development and improve the quality and efficiency of mental health services_-preventive, diagnostic and therapeutic-with a special interest in low SES children and their families.

The prevalence of depressive risk in the present sample was $4.2 \%$, when the cutoff point of 19 suggested by Kovacs [30] was taken as threshold. This figure is much lower than those reported in other studies which concluded to prevalence rates around $10 \%$ using the same cutoff point of CDI score $[17,28,36,43]$. When the cutoff point of 13 was taken as threshold, the prevalence rate was somewhat higher $(14.96 \%)$ than the prevalence figures of self-reported depressive morbidity obtained from studies in general population, but still much lower than those obtained from studies using the cutoff point of 13 of the CDI [17, 43]. Since previous studies[10, 24, 27, 48] indicate that CDI can be better used as a continuous measure of depressive symptoms [10] rather than as an accurate discriminatory (through cutoff scores) instrument for depression, further research using CDI along with other validated diagnostic measures for psychopathology in both clinical and nonclinical Greek populations (questionnaires and/or structured interviews) is needed. The particular cultural influences on children's depressive symptom reporting is an issue that should be further explored in future research in order to investigate whether lower mean cores in CDI (compared to studies in non-Greek populations) reflect lower rates of depressive symptoms, differences in the perception of the CDI items, or even cultural differences in the expression of depressive symptomatology.

To the extent that the Greek CDI can be used for the screening of depressive symptoms in non-clinical populations, we would suggest that the cutoff point of 15 , corresponding to 90th percentile, should be used as a threshold for further assessment. This statement does not imply that the cutoff point of 15 is indicative for presence or absence of a depressive disorder, but merely suggests a high probability of serious levels of depressive symptoms that need to be further evaluated mainly through validated structured diagnostic interviews for mood disorders, although there is a relative lack of instruments with appropriate psychometric properties reported in Greece [29].

The findings of the present study emphasize the need of establishing structures and services within the school context aiming at children's mental health promotion and provision of assistance to teachers, students and families. The wider school environment should act simultaneously at different levels of preventing depression by positively influencing children's psychological well-being, identifying students at risk and responding effectively to their difficulties. Furthermore, the Greek mental health system should urgently plan, implement and evaluate services for providing effective treatments responding to the unmet clinical needs suggested by the present study. The scarcity of child psychiatric facilities and the limited research work in evidence-based treatment effectiveness in the field of child and adolescent psychiatry in Greece are of major concern [53].

It should be acknowledged that the present study has a number of limitations. Firstly, the study relied exclusively on children from the general population. As a result, in order to extrapolate these results to populations with known psychopathology, the CDI psychometric properties in clinically referred Greek youths remain to be established. Second, CDI was not validated against other questionnaires detecting psychopathology. Finally, comparison of CDI scores with psychiatric diagnoses (as measured through standardised diagnostic interviews) would certainly have strengthened this study.

Despite the abovementioned limitations, the present results are encouraging providing evidence about the psychometric properties of the CDI and about the prevalence of children's depressive symptoms in Greece. Further validation of the CDI against other measures and psychiatric diagnoses will promote the utility of the screening programs in various Greek community and school settings.

Acknowledgments The project is co-funded by the European Social Fund \& National Resources, EPEAEK II, PYTHAGORAS.

\section{References}

1. Anderson JC, Williams S, McGee R, Silva PA (1987) DSM-III disorders in preadolescent children. Prevalence in a large sample from the general population. Arch Gen Psychiatry 44:69-76

2. Angold A, Rutter M (1992) Effects of age and pubertal status on depression in a large clinical sample. Dev Psychopathol 4:5-28

3. Association AP (1994) Diagnostic and statistical manual of mental disorders, 4th edn (DSM IV). American Psychiatric Association, Washington DC

4. Bibou-Nakou I, Kiosseoglou G, Stogiannidou A (2001) Strengths and difficulties of school-aged children in the family and school context. Psychology 8:506-525

5. Blazer DG, Kessler RC, McGonagle KA, Swartz MS (1994) The prevalence and distribution of major depression in a national community sample: the National Comorbidity Survey. Am J Psychiatry 151:979-986

6. Bor W, Najman JM, Andersen MJ, O'Callaghan M, Williams GM, Behrens BC (1997) The relationship between low family income and psychological disturbance in young children: an Australian longitudinal study. Aust NZ J Psychiatry 31:664-675 
7. Boyce W, Torsheim T, Currie C, Zambon A (2006) The Family Affluence Scale as a measure of national wealth: validation of an adolescent self report measure. Soc Indic Res 78:473-487

8. Brooks SJ, Kutcher S (2001) Diagnosis and measurement of adolescent depression: a review of commonly utilized instruments. J Child Adolesc Psychopharmacol 11:341-376

9. Charman T, Pervova I (2000) The internal structure of the Child Depression Inventory in Russian and UK schoolchildren. J Youth and Adolesc 30:41-51

10. Comer JS, Kendall PC (2005) High-end specificity of the children's depression inventory in a sample of anxiety-disordered youth. Depress Anxiety 22:11-19

11. Craighead WE, Smucker MR, Craighead LW, Ilardi SS (1998) Factor analysis of the Children's Depression Inventory in a community sample. Psychol Assess 10:156-165

12. Cronbach LJ (1984) Essentials of psychological testing. Harper \& Row, New York

13. Currie CE, Elton RA, Todd J, Platt S (1997) Indicators of socioeconomic status for adolescents: the WHO health behaviour in school-aged children survey. Health Educ Res 12:385-397

14. Davanzo P, Kerwin L, Nikore V, Esparza C, Forness S, Murrelle L (2004) Spanish translation and reliability testing of the Child Depression Inventory. Child Psychiatry Hum Dev 35:75-92

15. Doerfler LA, Feiner RD, Rowlison RT et al (1988) Depression in children and adolescents: a comparative analysis of the utility and construct validity of two assessment measures. J Consult Clin Psychology 56:769-772

16. Flouri E, Tzavidis N (2008) Psychopathology and prosocial behavior in adolescents from socio-economically disadvantaged families: the role of proximal and distal adverse life events. Eur Child Adolesc Psychiatry 17:498-506

17. Frigerio A, Pesenti S, Molteni M, Snider J, Battaglia M (2001) Depressive symptoms as measured by the CDI in a population of northern Italian children. Eur Psychiatry 16:33-37

18. Gandek B, Ware JE (1998) Methods for validating and norming translations of health status questionnaires: the IQOLA project approach for the IQOLA project group health assessment. J Clin Epidemiol 51:953-959

19. Garvin V, Leber D, Kalter N (1991) Children of divorce: predictors of change following preventive intervention. Am J Orthopsychiatry 61:438-447

20. Guttman L (1945) A basis for analysing test-retest reliability. Psychometrica 10:255-282

21. Hecht DB, Inderbitzen HM, Bukowski AL (1998) The relationship between peer status and depressive symptoms in children and adolescents. J Abnorm Child Psychol 26:153-160

22. Ivarsson T, Svalander P, Litlere O (2006) The Children's Depression Inventory (CDI) as measure of depression in Swedish adolescents. A normative study. Nord J Psychiatry 60:220-226

23. Kapi A, Veltsista A, Kavadias G, Lekea V, Bakoula C (2007) Social determinants of self-reported emotional and behavioral problems in Greek adolescents. Soc Psychiatry Psychiatr Epidemiol 42:594-598

24. Kazdin AE (1987) Children's Depression Scale: validation with child psychiatric inpatients. J Child Psychol Psychiatry 28:29-41

25. Kazdin AE (1989) Identifying depression in children: a comparison of alternative selection criteria. J Abnorm Child Psychol $17: 437-454$

26. Kazdin AE, Colbus D, Ridgers A (1986) Assessment of depression and diagnosis of depressive disorder among psychiatrically disturbed children. J Abnorm Child Psychology 14:499-515

27. Kazdin AE, Esveldt-Dawson K, Unis AS, Rancurello MD (1983) Child and parent evaluations of depression and aggression in psychiatric inpatient children. J Abnorm Child Psychol $11: 401-413$
28. Kleftaras G, Didaskalou E (2006) Incidence and teachers' perceived causation of depression in primary school in Greece. Sch Psychol Int 27:296-314

29. Kolaitis G, Korpa T, Kolvin I, Tsiantis J (2003) Schedule for affective disorders and schizophrenia for school-age childrenpresent episode (K-SADS-P): a pilot inter-rater reliability study for Greek children and adolescents. Eur Psychiatry 18:374-375

30. Kovacs M (1992) Manual for the Children's Depression Inventory (CDI). Psychopharmacol Bull 21:995-998

31. Kovacs M (1981) Rating scales to assess depression in schoolaged children. Acta Paedopsychiatr 46:305-315

32. Kovacs M, Feinberg TL, Crouse-Novak MA, Paulauskas SL, Finkelstein R (1984) Depressive disorders in childhood. I. A longitudinal prospective study of characteristics and recovery. Arch Gen Psychiatry 41:229-237

33. Larson B, Melin L (1992) Prevalence and short-term stability of depressive symptoms in schoolchildren. Acta Psychiatr Scand 85:17-22

34. Levitt JM, Saka N, Romanelli LH, Hoagwood K (2007) Early identification of mental health problems in schools: the status of instrumentation. J Sch Psychol 45:163-191

35. Lobovits DA, Handal PJ (1985) Childhood depression: prevalence using DSM-III criteria and validity of parent and child depression scales. J Pediatr Psychol 10:45-54

36. Madianos M (1998) Health and Hellenic Society: empirical research. National Centre for Social Research, Athens

37. McDonald VM, Tsiantis J, Achenbach TM, Motti-Stefanidi F, Richardson SC (1995) Competences and problems reported by parents of Greek and American children. Euro Child Adol Psych $4: 1-13$

38. McHorney CA, Ware JE, Lu JF, Sherbourne CD (1994) The MOS 36-item Short-Form Health Survey (SF-36): III. Tests of data quality, scaling assumptions, and reliability across diverse patient groups. Medical Care 32:40-66

39. McMunn AM, Nazroo JY, Marmot MG, Boreham R, Goodman R (2001) Children's emotional and behavioural well-being and the family environment: findings from the Health Survey for England. Soc Sci Med 53:423-440

40. Mossialos E, Allin S, Davaki K (2005) Analysing the Greek health system: a tale of fragmentation and inertia. Health Econ 14:S151-S168

41. Myers K, Winters NC (2002) Ten-year review of rating scales. II: scales for internalizing disorders. J Am Acad Child Adolesc Psychiatry 41:634-659

42. Nunnally JC, Bernstein IH (1994) Psychometric theory. McGrow-Hill Book, New York

43. Poli P, Sbrana B, Marcheschi M, Masi G (2003) Self-reported depressive symptoms in a school sample of Italian children and adolescents. Child Psychiatry Hum Dev 33:209-226

44. Reynolds WM (1994) Assessment of depression in children and adolescents by self-report questionnaires. In: Reynolds WM, Johnston HF (eds) Handbook of depression in children and adolescents. Plenum Press, New York/London, pp 209-234

45. Roberts RE, Roberts CR, Chen YR (1997) Ethnocultural differences in prevalence of adolescent depression. Am J Community Psychol 25:95-110

46. Roussos A, Karantanos G, Richardson C, Hartman C, Karajiannis D, Kyprianos S, Lazaratou H, Mahaira O, Tassi M, Zoubou V (1999) Achenbach's child behavior checklist and teachers' report form in a normative sample of Greek children 6-12 years old. Eur Child Adolesc Psychiatry 8:165-172

47. Samm A, Värnik A, Tooding L-M, Sisask M, Kölves K, von Knorring A-L (2007) Children's Depression Inventory in Estonia. Single items and factor structure by age and gender. Eur Child Adolesc Psychiatry 17:162-170 
48. Saylor CF, Finch AJ Jr, Spirito A, Bennett B (1984) The children's depression inventory: a systematic evaluation of psychometric properties. J Consult Clin Psychol 52:955-967

49. Smucker MR, Craighead WE, Craighead LW, Green BJ (1986) Normative and reliability data for the Children's Depression Inventory. J Abnorm Child Psychol 14:25-39

50. Sorensen MJ, Frydenberg M, Thastum M, Thomsen PH (2005) The Children's Depression Inventory and classification of major depressive disorder: validity and reliability of the Danish version. Eur Child Adolesc Psychiatry 14:328-334

51. Thomson C, Currie C, Todd J, Elton R (1999) Changes in HIV/ AIDS education, knowledge and attitudes among Scottish 1516 year olds, 1990-1994: findings from the WHO: health behaviour in school-aged children study (HBSC). Health Educ Res 14:357-370

52. Timbremont B, Braet C, Dreessen L (2004) Assessing depression in youth: relation between the Children's Depression Inventory and a structured interview. J Clin Child Adolesc Psychol 33:149-157
53. Trowell J, Joffe I, Campbell J, Clemente C, Almqvist F, Soininen M, Koskenranta-Aalto U, Weintraub S, Kolaitis G, Tomaras V, Anastasopoulos D, Grayson K, Barnes J, Tsiantis J (2007) Childhood depression: a place for psychotherapy. An outcome study comparing individual psychodynamic psychotherapy and family therapy. Eur Child Adolesc Psychiatry 16:157-167

54. Trust SACotMO (2002) Assessing health status and quality-oflife instruments: attributes and review criteria. Qual Life Res 11:193-205

55. Twenge JM, Nolen-Hoeksema S (2002) Age, gender, race, socioeconomic status, and birth cohort differences on the children's depression inventory: a meta-analysis. J Abnorm Psychol 111:578-588

56. Weiss B, Weisz JR, Politano M, Carey M, Nelson WM, Finch AJ (1991) Developmental differences in the factor structure of the Children's Depression Inventory. J Consult Clin Psychol 3:38-45 